\title{
Transition Readiness in Adolescents and Young Adults With Chronic Rheumatic Disease in Oman: Today's Needs and Future Challenges
}

Reem Abdwani ( $\square$ rabdwani@squ.edu.om )

Sultan Qaboos University https://orcid.org/0000-0002-1189-1959

Rumaitha Al Sabri

OMSB: Oman Medical Speciality Board

\section{Zawan Zawan Alhasni}

OMSB: Oman Medical Speciality Board

\section{Seyad Rizvi}

SQU: Sultan Qaboos University

\section{Humaid Al Wahshi}

The Royal Hospital

\section{Batool Al Lawati}

Sultan Qaboos University

\section{Safiya Al Abrawi}

The Royal Hospital

\section{Yasser Wali}

Sultan Qaboos University

\section{Mona Al Sadoon}

Sultan Qaboos University

\section{Research article}

Keywords: Transitional Care, Adolescents, Oman

Posted Date: January 10th, 2022

DOI: https://doi.org/10.21203/rs.3.rs-1224089/v1

License: (c) (i) This work is licensed under a Creative Commons Attribution 4.0 International License. Read Full License

Version of Record: A version of this preprint was published at Pediatric Rheumatology on April 12th, 2022. See the published version at https://doi.org/10.1186/s12969-022-00687-6. 


\section{Abstract}

\section{Introduction:}

In Oman, the "transfer" healthcare rather than the "transition" of health care of adolescents to adult care occurs at a young age, like many other GCC countries for cultural reasons. In order to address this concern, this study was conducted to determine the transition readiness skills of adolescents and young adults with childhood onset rheumatic diseases using a cross-cultural adaptation of the UNC TRXANSITION scale.

\section{Methods:}

We used a professionally translated/back translated, provider-administered UNC TR ANSITION Scale. This 32-question scale measures HCT in ten domains including knowledge about diagnosis or treatment, diet, reproductive health, school/work, insurance, ability to self-manage and looking for new health providers. The maximum transitional score of 10 , was categorized as low (1-4), moderate (4 - 7) and high (7-10) transitional readiness scores.

\section{Results:}

We enrolled 81 Omani adolescents and young adults (AYA) with chronic childhood onset rheumatic diseases. The cohort consisted of $79 \%$ females, with mean age of 15.8 years $( \pm 3.53)$ and mean disease duration of 6.95 years $( \pm 4.83)$. Our cohort's overall mean score is low $5.22( \pm 1.68)$. Only $14.8 \%$ of the cohort achieved a high transition score $\geq 7$ ). Significant direct relationship was observed between age and the mean transition readiness score $(r=.533, P<.001)$. The mean transition readiness score in the younger age group (10-13 years) was $4.07( \pm 1.29)$, the middle age group (14-18 years) was $5.43( \pm 1.27)$, while the older age group (19-21 year), was $6.12( \pm 1.81)$, Mean transition score of youngest age group was found to be significantly lower than the other two age groups $(p=.003)$.

\section{Conclusion:}

Overall, the transition readiness of AYA in Oman is low compared to other western countries indicating the need to initiate a health care transition preparation program for patients with chronic diseases across the country. In addition, we need to establish regional guidelines to address the transitional age policy to be in line to international recommendations.

\section{Introduction:}

Advances in health care over the last decades have led to substantial improvement in the outcome of patients with childhood onset rheumatic diseases due to the availability of more efficacious therapies and improved treatment strategies (1-5). However, the transition of adolescent and young adults (AYA) with rheumatic diseases continues to be challenging and complex. Over half of young patients transferred to an adult rheumatologist have inadequate follow-up (6). This is worrisome, especially that 
over $50 \%$ of JIA patients enter adult care with flare of disease, whereas a significant proportion of childhood onset SLE patients develop disease flare within one year of transitioning to adult care (7-9). Also, young adults with rheumatic disease are less likely to have college education, maintain employment and have lower income than their peers $(10,11)$. Hence, effective transitional care for AYA with rheumatic disease is fundamental to rheumatology care provision.

Health care transition (HCT) is defined as the purposeful and planned movement of adolescents and young adults with chronic physical and medical conditions from child-centered to adult oriented healthcare systems (12). Transition of care is a multifaceted active process that focuses on the medical, psychosocial, educational, and vocational needs of adolescents as they move from child to adult centered care. This is in contrast to transfer, which is an event rather than a process. Transition programs for adolescents with chronic diseases aim to provide comprehensive, coordinated, uninterrupted health care that is age and developmentally appropriate. They promote skills in communication, decision making, and self-care and therefore enhance a young person's control and independence. HCT can be characterized by a three stage process 1 ) preparation phase, a lengthy phase which starts in early adolescence, 2) transfer of care phase, usually in late adolescence and 3) integration into adult health care phase, which continues following the transfer (13). A fundamental element of the HCT process is preparing young adolescents how to manage their own health. This involves the adolescent, family members, as well as the pediatric and adult healthcare provider as equally engaged collaborators. By using transition readiness assessment tools, providers can objectively evaluate the knowledge and skills required for adolescent and young adults to manage their own health.

There are several validated transition readiness assessment tools for AYA with chronic diseases have been described in the literature. A recent systematic review identified nineteen tools in the literature, including the Transition Readiness Assessment Questionnaire $(14,15)$, the UNC TRxANSITION Scale (16), the STARx Questionnaire (17), the Am I ONTRAC for Adult Care questionnaire (18), TRANSITIONQ (19), and the Adolescent Assessment of Preparation for Transition (20). Among the nineteen tools, the UNC TRXANSITION Scale, is the only tool that is administered to the adolescent by a healthcare provider; the other 18 tools are self-reported (21). The UNC TRXANSITION Scale is a disease-neutral tool that can be used in the clinical setting. It is a reliable and valid tool that measures health-care transition knowledge, skill mastery and monitors progression in multidimensional fashion (22). A recent systematic review on transition readiness showed that UNC TRXANSITION Index scale has been used by several studies (2325).

Within the healthcare system in Oman, like many other GCC countries in the region, transitional health care is not well developed. There is no standard transition process for patients with chronic diseases. The "transfer" of care adolescents to adult care is an "event" that occurs at the age 12-13 years, like many other Arabic/Muslim countries for cultural reasons. There is also paucity of literature on transitional care of patients with chronic disease from this region. In order to address this issue, this study was conducted to determine the transition readiness skills in patients with childhood onset rheumatic diseases using a cross-cultural adaptation of the UNC TRXANSITION Scale and to determine the predictive factors 
contributing to high transition readiness skills for better continuity of care in these patients, which can be beneficial in making future recommendations.

\section{Method:}

\section{Instrument and validation:}

The UNC TRXANSITION Scale ${ }^{\text {TM }}$ is validated and reliable in both the pediatric and adult patients. The scale is composed of 32 questions which are distributed in 10 domains which are knowledge on 1) Type of illness $(T), 2)$ Medications $(R x), 3$ ) Adherence $(A), 4)$ Nutrition $(N), 5)$ Self-management skills $(S), 6)$ Informed reproduction issues (I), 7) Trade/school issues $(T), 8)$ Insurance issues (I), 9) Ongoing support

$(O)$ and 10$)$ New health care provider identification $(N)$. In this scale, the total score of transition readiness and domain scores are computed based on clinician ratings of patient responses. Each question in the scale is scored as follows: 0 points indicates no knowledge or self-management skills, 0.5 points means some knowledge or self-management skills, or 1 point reveals complete knowledge or self-management skill. A total score is calculated ranged between 0 and 10 , while the transition readiness assessment scores were categorized as low $(0-<4)$, moderate $(4-7)$ and high $(7-10)$. For the study, trained research assistants administered the questions of UNC TRXANSITION Scale in the form of an interview. We made sure that AYA answered these questions independently without the input of their parents.

The original English-language version of the UNC TRxANSITION Scale was translated to Arabic language, for better communication with patients, using established forwards and backwards translation methods. Two independent translators each translated the English language version of the scale into Arabic. Then a committee of Arabic-speaking researchers compared these translations both with each other and with the original English version in order to create a first draft. Next, the two independent translators translated the draft back into English and the committee again compared both back-translated versions together and to the first draft to ensure the accuracy of the content. A second draft was then created and examined to resolve any ambiguities. The second draft, along with the original English-language version of the UNC TRXANSITION Scale, was submitted to three pediatricians and two physicians to check face validity. Some minor modifications were made based on their feedback. The final Arabic version of the scale was deemed to reflect an accurate translation of the items in the original UNC TRXANSITION Scale. A pretesting of the instrument was subsequently conducted among 10 healthy children (six males and four females) to assess the clarity of the items in the final Arabic version of the scale and estimate the time required for the interview. The results indicated that the Arabic scale was well understood by all and was time efficient, taking approximately 20 minutes to administer.

\section{Data collection:}

After obtaining informed consent from patients and parents, we recruited $(n=81)$ Omani AYA from Sultan Qaboos University Hospital and Royal Hospital, between 10 to 21 years of age and diagnosed with a chronic rheumatic condition for at least 1 year. We recruited a similar number of patients in three age groups; younger (10 -13 years), middle (14-18 years) and older (19-21 years) age groups. The diagnoses 
of patients included juvenile idiopathic arthritis, systemic lupus erythematosus and other childhood onset rheumatic diseases such systemic vasculitis and juvenile dermatomyositis. Exclusion criteria were major cognitive disorders or any comorbidity that interferes with future self-management of health. The information collected on sociodemographic factors included gender, age, type of school, mother's education level, father's education level, mother's occupation, father's occupation, type of family, order among siblings, presence of the disease in siblings and income was collected.

\section{Statistical analysis:}

Data base for the study was created in IBM SPSS 23 software. In the UNC TRXANSITION Scale for AYA; as all questions were not applicable for all subjects, hence, the proportion score for the subjects was obtained by including only the relevant questions for the respective subjects. Kolmogorov-Smirnov test was used to test the normality of the variable in different categories of the demographic characteristics. Independent sample t-test or ANOVA were used to test the significance of the difference between the observed means of the categories, if the distribution pattern was found normal, otherwise Mann-Whitney $\mathrm{U}$ or Kruskal Wallis $\mathrm{H}$ tests were applied, respectively. Pearson Correlation formula was used to evaluate the degree of linear relationship between age and transition readiness score. $\mathrm{P} \leq .05$ has been considered as significant

\section{Results:}

The study sample of 81 patients were distributed in three age groups in similar numbers; $(n=26$, in 10-13 years $(n=26), 14-18$ years $(n=29)$ and in 19-21 years $(n=26)$. The mean age of the cohort was 15.80 years $( \pm 3.53)$ and the mean age of disease onset was 8.81 years $( \pm 5.51)$ with mean disease duration of cohort was 6.95 years ( \pm 4.8 years). A total of 64 participants were female $(79 \%)$. Majority patient originate from Muscat region $(n=27,33 \%)$, followed by Al Shariqiya and Al Batina region $(n=21,26 \%)$ equally. The cohort of patients with chronic rheumatic disease consist of patients diagnosed with childhood onset systemic lupus erythematosus ( $n=50,62 \%)$, juvenile idiopathic arthritis $(n=23,28 \%)$, and other chronic childhood onset rheumatic diseases $(n=8,10 \%)$. There was no significant difference between age groups in all sociodemographic variables; hence the results are described for the whole sample in Table 1. Father's educational level was college degree or higher in $41 \%$ and $68 \%$ were employed, while the mother's educational level was college degree or higher in $28 \%$ and $21 \%$ were employed. The total household income was less than 1000 Omani Rials ( $\$ 2500$ US dollars) per month in $53 \%$ of the cohort. 
Table 1

Sociodemographic of adolescent and young adults with chronic rheumatic diseases.

\begin{tabular}{|c|c|c|}
\hline & Frequency $(\mathrm{n}=81)$ & percentage \\
\hline \multicolumn{3}{|l|}{ Gender } \\
\hline Male & 17 & $21 \%$ \\
\hline Female & 64 & $79 \%$ \\
\hline \multicolumn{3}{|l|}{ Age groups } \\
\hline $10-13$ years & 26 & $32 \%$ \\
\hline $14-18$ years & 29 & $36 \%$ \\
\hline $19-21$ years & 26 & $32 \%$ \\
\hline \multicolumn{3}{|l|}{ Region } \\
\hline Muscat & 27 & $33 \%$ \\
\hline Al Sharqiya & 21 & $26 \%$ \\
\hline Al Batina & 21 & $26 \%$ \\
\hline Al Dakhlia & 5 & $6 \%$ \\
\hline Muscandam \& Al Wusta & 4 & $5 \%$ \\
\hline Dhofar & 3 & $4 \%$ \\
\hline \multicolumn{3}{|c|}{ Father Educational Level Illiterate } \\
\hline School & 14 & $17 \%$ \\
\hline College and higher & 34 & $42 \%$ \\
\hline \multirow[t]{2}{*}{ Employment } & 33 & $41 \%$ \\
\hline & 55 & $68 \%$ \\
\hline \multicolumn{3}{|l|}{ Mother Education Level } \\
\hline Illiterate & 17 & $21 \%$ \\
\hline School & 41 & $51 \%$ \\
\hline College and higher & 23 & $28 \%$ \\
\hline Employment & 17 & $21 \%$ \\
\hline \multicolumn{3}{|l|}{ Household income/month } \\
\hline$<1000$ RO & 43 & $53 \%$ \\
\hline $1000-2000$ & 29 & $36 \%$ \\
\hline
\end{tabular}




\begin{tabular}{|lcc|}
\hline 2000 RO & 9 & $11 \%$ \\
\hline Transition readiness score & & \\
Low score (0-4) & 18 & $22 \%$ \\
Medium score (4-7) & 51 & $63 \%$ \\
High score (7-10) & 12 & $15 \%$ \\
\hline
\end{tabular}

There was a statistical significance within the transitional readiness index score across age groups as shown in Figure 1. The overall mean score for the sample is $5.22( \pm 1.68)$. The mean scores of our patients belonging to younger, middle and older age groups were all in the 'moderate category' of transition readiness scale (4-7). However, there is a steady increase in the overall mean score with increase in age group, with the mean score of $4.07( \pm 1.3)$ in the younger, $5.43( \pm 1.27)$ in the middle and $6.12( \pm 1.8)$ in the older age group $(p<0.001)$. Further analysis of the three age groups as displayed in Table 2. The overall cohort $(n=81)$ achieved a transition readiness index score was defined as low in $22 \%$; medium in $64 \%$ and high in $14.8 \%$. $(p=0.0004)$. The cohort with a high transition score, majority belonged to the older group while only one of the patients in the younger age group had a high transitional index score. Interestingly, in the older age group, a high transition readiness score was achieved in only $30.8 \%$ of the cohort, while the majority had a moderate score $61.5 \%$.

Table 2

\begin{tabular}{|lllll|}
\hline Transitional Readiness Index Score Categories in different age Groups \\
\hline Transitional readiness & \multicolumn{3}{r}{ Age group $(\mathrm{n}=\mathbf{8 1})$} & Total \\
\cline { 2 - 4 } categories & $\mathbf{1 0 - 1 3}$ yrs & $\mathbf{1 4 - 1 8}$ yrs & $\mathbf{1 9 - 2 1}$ yrs & \\
\hline Low score (0-4) & $(\mathrm{n}=12)$ & $(\mathrm{n}=4)$ & $(\mathrm{n}=2)$ & $(\mathrm{n}=18)$ \\
& $46.2 \%$ & $13.8 \%$ & $7.7 \%$ & $22.2 \%$ \\
\hline Medium score (4-7) & $(\mathrm{n}=13)$ & $(\mathrm{n}=22)$ & $(\mathrm{n}=16)$ & $(\mathrm{n}=52)$ \\
& $50.0 \%$ & $75.9 \%$ & $61.5 \%$ & $64.2 \%$ \\
\hline High score (7-10) & $(\mathrm{n}=1)$ & $(\mathrm{n}=2)$ & $(\mathrm{n}=9)$ & $(\mathrm{n}=12)$ \\
& $3.8 \%$ & $9.5 \%$ & $26.5 \%$ & $14.8 \%$ \\
\hline Total & 26 & 29 & 26 & 81 \\
\hline
\end{tabular}

The detailed comparison of the statistically significant mean transitional scores across different age groups in the subdomains of UNC TRXANSITION Scale domains are highlighted in Figure 2. For the overall mean transition score, a statistically significant difference was found between the age groups 
$(\mathrm{p}<0.0004)$ and the difference in mean scores between any two age groups on post-hoc pairwise analysis was also statistically significant. In section wise analysis of the 10 subdomains across the three age groups, the statistically significant sections include: Type of illness, Self-management skills, Issues of reproduction, Insurance issues and New healthcare provider identification as displayed in Figure 2. Also, the overall mean transition scores have statistically significant difference in the mean scores across various age categories with lowest scores in the 10 to 13 age group and highest scores in the 18 to 21 years group. The post-hoc pairwise analysis locates the differences in scores between any two age groups across the 10 domains are displayed in Table 3 . In the statistically significant domains which include the type of illness, the post hoc analysis showed the mean transitional scale in the younger age group 0.42 (SD0.25), middle age group 0.72 (SD 0.24) and older age group 0.82 (SD 0.28) with $p<0.001$. The self-management skills domain, showed the mean transitional scale in the younger age group 0.33 (SD 0.25), middle age group 0.60 (SD 0.25) and the older age group 0.74 (SD 0.24) with $p<0.001$. The informed reproduction issues domain showed, the mean score in the younger age group 0.00 (SD 0 ), middle age group .02 (SD 0.05) and the older age group 0.26 (SD 0.34) with $p<0.001$. The insurance domain showed, the mean score in the younger age group 0.12 (SD 0.17), middle age group 0.29 (SD 0.28 ) and the older age group 0.38 (SD 0.30) with $p=0.002$. While, the new healthcare provider identification domain showed, the mean score in the younger age group 0.26 (SD 0.30), middle age group 0.54 (SD 0.37) and older age group 0.63 (SD 0.41) with $p=0.001$. As Figure 3 depicts, the transition index score was the highest in the following domains; Adherence 0.81 (SD 0.21), Medication 0.76 (0.24) and Trade/School 0.75 (0.43); while the following domains had the lowest transition readiness index score: Issue on reproduction 0.09 (SD 0.22), Insurance 0.26 (SD 0.28) and Nutrition 0.28 (0.36). 
Table 3

Mean UNC TRANSITION Readiness Index and Post Hoc comparison among different age groups

\begin{tabular}{|c|c|c|c|c|}
\hline Characteristic & $\begin{array}{l}\text { Age } \\
\text { groups }\end{array}$ & Mean \pm SD & $\begin{array}{l}p \\
\text { value }\end{array}$ & $\begin{array}{l}\text { p-values for Post-hoc } \\
\text { comparisons }\end{array}$ \\
\hline \multirow[t]{3}{*}{ Type of illness } & a & $\begin{array}{l}0.42 \text { SD } \\
(0.25)\end{array}$ & \multirow[t]{3}{*}{$\begin{array}{l}P= \\
0.000\end{array}$} & \multirow{3}{*}{$\begin{array}{l}a \& b(p=0.002) \\
a \& c(p=0.000) \\
b \& c(p=0.203)\end{array}$} \\
\hline & b & $\begin{array}{l}0.69 \mathrm{SD} \\
(0.24)\end{array}$ & & \\
\hline & c & $\begin{array}{l}0.81 \mathrm{SD} \\
(0.27)\end{array}$ & & \\
\hline \multirow[t]{3}{*}{ Medications } & a & $\begin{array}{l}0.69 \mathrm{SD} \\
(0.24)\end{array}$ & \multirow[t]{3}{*}{$\begin{array}{l}P= \\
0.245\end{array}$} & \multirow{3}{*}{$\begin{array}{l}a \& b(p=0.587) \\
a \& c(p=0.217) \\
b \& c(p=0.853)\end{array}$} \\
\hline & $b$ & $\begin{array}{l}0.76 \text { SD } \\
(0.246)\end{array}$ & & \\
\hline & c & $\begin{array}{l}0.789 \mathrm{SD} \\
(0.23)\end{array}$ & & \\
\hline \multirow[t]{3}{*}{ Adherence } & a & $\begin{array}{l}0.78 \text { SD } \\
(0.23)\end{array}$ & \multirow[t]{3}{*}{$\begin{array}{l}P= \\
0.698\end{array}$} & \multirow{3}{*}{$\begin{array}{l}a \& b(p=0.896) \\
a \& c(p=0.673) \\
b \& c(p=0.943)\end{array}$} \\
\hline & $b$ & $\begin{array}{l}0.81 \mathrm{SD} \\
(0.177)\end{array}$ & & \\
\hline & c & $\begin{array}{l}0.828 \mathrm{SD} \\
(0.207)\end{array}$ & & \\
\hline \multirow[t]{3}{*}{ Nutritional restrictions } & a & $\begin{array}{l}0.288 \mathrm{SD} \\
(0.325)\end{array}$ & \multirow[t]{3}{*}{$\begin{array}{l}P= \\
0.845\end{array}$} & \multirow{3}{*}{$\begin{array}{l}a \& b(p=0.959) \\
a \& c(p=0.950) \\
b \& c(p=0.833)\end{array}$} \\
\hline & $b$ & $\begin{array}{l}0.317 \mathrm{SD} \\
(0.387)\end{array}$ & & \\
\hline & c & $\begin{array}{l}0.26 \mathrm{SD} \\
(0.369)\end{array}$ & & \\
\hline \multirow[t]{3}{*}{ Self-management skills } & a & $\begin{array}{l}0.327 \text { SD } \\
(0.247)\end{array}$ & \multirow[t]{3}{*}{$\begin{array}{l}P= \\
0.000\end{array}$} & \multirow{3}{*}{$\begin{array}{l}a \& b(p=0.003) \\
a \& c(p=0.000) \\
b \& c(p=0.048)\end{array}$} \\
\hline & $b$ & $\begin{array}{l}0.567 \mathrm{SD} \\
(0.27)\end{array}$ & & \\
\hline & c & $\begin{array}{l}0.729 \text { SD } \\
(0.22)\end{array}$ & & \\
\hline \multirow[t]{2}{*}{ Informed reproduction issues } & a & $\begin{array}{l}0.00 \mathrm{SD} \\
(0.00)\end{array}$ & \multirow[t]{2}{*}{$\begin{array}{l}P= \\
0.000\end{array}$} & \multirow{2}{*}{$\begin{array}{l}a \& b(p=1.000) \\
a \& c(p=0.000) \\
b \& c(p=0.001)\end{array}$} \\
\hline & $b$ & $\begin{array}{l}0.00 \text { SD } \\
(0.00)\end{array}$ & & \\
\hline
\end{tabular}




\begin{tabular}{|c|c|c|c|c|}
\hline Characteristic & $\begin{array}{l}\text { Age } \\
\text { groups }\end{array}$ & Mean \pm SD & $\begin{array}{l}p \\
\text { value }\end{array}$ & $\begin{array}{l}\text { p-values for Post-hoc } \\
\text { comparisons }\end{array}$ \\
\hline & c & $\begin{array}{l}0.216 \text { SD } \\
(0.31)\end{array}$ & & \\
\hline \multirow{3}{*}{ Trade/ School issues } & & & \multirow{3}{*}{$\begin{array}{l}P= \\
0.563\end{array}$} & a \& c $(p=0.996)$ \\
\hline & b & $(0.48)$ & & $b \& c(p=0.612)$ \\
\hline & c & $\begin{array}{l}0.779 \text { SD } \\
(0.41)\end{array}$ & & \\
\hline \multirow[t]{3}{*}{ Insurance issues } & a & $\begin{array}{l}0.12 \text { SD } \\
(0.17)\end{array}$ & \multirow[t]{3}{*}{$\begin{array}{l}P= \\
0.002\end{array}$} & \\
\hline & $b$ & $\begin{array}{l}0.28 \mathrm{SD} \\
(0.255)\end{array}$ & & $b \& c(p=0.470)$ \\
\hline & c & $\begin{array}{l}0.36 \mathrm{SD} \\
(0.308)\end{array}$ & & \\
\hline \multirow[t]{3}{*}{ Ongoing support } & a & $\begin{array}{l}0.769 S D \\
(0.29)\end{array}$ & \multirow[t]{3}{*}{$\begin{array}{l}P= \\
0.577\end{array}$} & \\
\hline & b & $\begin{array}{l}0.857 \mathrm{SD} \\
(0.32)\end{array}$ & & $\begin{array}{l}a \& c(p=0.6 / 2) \\
b \& c(p=0.974)\end{array}$ \\
\hline & c & $\begin{array}{l}0.838 \mathrm{SD} \\
(0.319)\end{array}$ & & \\
\hline \multirow[t]{3}{*}{$\begin{array}{l}\text { New health care providers } \\
\text { identification }\end{array}$} & a & $\begin{array}{l}0.260 \mathrm{SD} \\
(0.295)\end{array}$ & \multirow[t]{3}{*}{$\begin{array}{l}P= \\
0.002\end{array}$} & $a \& b(p=0.009)$ \\
\hline & b & $\begin{array}{l}0.583 \mathrm{SD} \\
(0.338)\end{array}$ & & $\begin{array}{l}a \& c(p=0.003) \\
b \& c(p=1.00)\end{array}$ \\
\hline & c & $\begin{array}{l}0.581 S \mathrm{SD} \\
(0.42)\end{array}$ & & \\
\hline
\end{tabular}

\section{Discussion:}

Adolescents make up more than $25 \%$ of the population of Gulf Cooperation Council (GCC) countries, a percentage that is far higher than that in other high-income countries, yet their health status and health care needs are not given proportional attention in the region (26). While there is progress in the health systems in GCC, a gap exists between the training, knowledge and skill-set of existing health-care providers and the needs of the adolescents for whom they provide care (27). Many health care providers in the region have limited or no training in adolescent health care. Therefore, adolescents tend to be "transferred" rather than "transitioned" to the adult care system at a very young age without the 
necessary health care transition process. This poses a challenge on the outcome of adolescents with chronic disease.

There are major differences in the pediatric and adult health care models that need to be understood to manage the expectations of both patients and healthcare providers for the transitional process to be successful. Pediatric care tends to be a family-centered approach, whereas adult care tends to be patient centered. Similarly, pediatric care is developmentally focused and adapts to the growing needs of children and adolescents, whereas adult care tends to be more disease focused. Moreover, pediatric team approach tends to be multidisciplinary, whereas adult care is reliant on referrals to other services. In addition, the clinical settings are perceived as nurturing, and they focus on psychosocial support for adolescents and their families, whereas adult services offer a more cognitive and information-based approach to care (28-29). These differences in approaches to care require adjustment and skills in selfcare and advocacy that adolescents must develop to transition successfully from the pediatric health care system to the adult health care system. However, since the "transfer of care" in Oman, like many other GCC countries, occurs at an early age, this adjustment process does not develop for both AYA as well as healthcare providers.

The American Academy of Pediatrics (AAP), the American Academy of Family Physicians (AAFP), and the American College of Physicians (ACP), developed transitional care policy/guidelines which describe 6 core elements of transition process and suggested an age range for each of those 6 elements to occur (30). It consists of the following steps 1 ) discussing the transition guidelines (12-14 years), 2) transition tracking and monitoring (14-18 years), 3) transition readiness assessment with validated tools (14-18 years), 4) transition planning (14-18 years), 5) transfer of care (18-21 years), and finally tracking 6) transfer completion (18-23 years). In our cohort AYA patients, who are followed at the two main pediatric and adult rheumatology centers in Oman, who have had no formal transitional services, the transfer event occurs at the age of 13 years, which is the suggested age to begin the discussion of transitional policy and process in most western countries rather than the actual transfer that occurs in this region of the world.

The overall mean transitional score for our cohort was 5.22 (SD 1.68) which is overall lower than other studies using UNC TR ANSITION Scale transitional tool assessment (22-25). In our cohort, the mean transitional score at the current 'transfer' age is $4.07( \pm 1.27)$ which is considered to be a low score, only one of the patients in this age group had a high transitional score. This patient had a disease onset at 3 years with disease duration over 10 years at the time of transfer, in addition to both parents having a high educational level, which might have contributed to the favorable results. However, there is a gradual trend in increase in the mean transitional score to $6.12( \pm 1.81)$ in the older age group. Despite the increasing trend of transitional scores, only $30.8 \%$ of patients in the older group were considered to have a high transitional score. Of the 10 subdomains in UNC TRXANSITION scale with lowest score included the domains of Insurance and Issue of Reproduction. Given that healthcare service is free to all Oman citizens within government institutions, the relevance of insurance is applicable to Omani citizens seeking services in private hospitals. Some companies offer insurance to employees while others extend the 
insurance to cover family members. This might have caused confusion in the insurance domain as AYA were not aware of this issue. With regards to the Issues of Reproduction, this was only addressed to females over 19 year of age and were culturally adapted.

Overall, our results reflect that our AYA patients with chronic rheumatic diseases are not adequately prepared for the 'transfer' to adult care at the current cut-off age of 13 years. It emphasizes the need to initiate transitional services within the country, which should commence by increasing the transfer age to 18-21 years as evidenced by the results of our study and keeping in par with international recommendations $(30,31)$. Similarly, the relatively lower percentage of patients in the older group with a high transitional score, suggest that further educational measures at an earlier age are needed to improve the transitional process. Greater emphasis in education should be in domains with the lowest mean transitional scores. The implementation of transitional care into practice in Oman needs to be evidence based and identifies effective measures of transitional care and quality indicators to measure success.

The lack of transition care services is a global challenge and not limited to this region of the world. In a recent survey that focuses on current practices in transitional care among 115 pediatric rheumatology centers in 22 European Union countries, 23\% responded that their centers did not offer transition services, however, the majority agreed that a formal process in transitioning patients to adult care is necessary (32). Similarly, a recent survey in North America among pediatric and adult rheumatologists was conducted among Childhood Arthritis and Rheumatology Research Alliance (CARRA) members. Of the $217 / 398$ members responded, $63 \%$ did not consistently address healthcare transition with patients, only $17 \%$ had a transition policy and only $31 \%$ used a transitional tool, while a dedicated transition clinic was available in $23 \%$ of centers. In contrast to our study, the most common age to begin transition planning was 15-17 (49\%), and most providers transferred patients at age 21 or older (75\%) (33).

This study is not without any limitations. The cross-sectional design provides a one-time assessment. Similarly, we conducted the study on an exclusive sample of patients diagnosed with chronic rheumatological conditions. Ideally, a longitudinal study on a wide spectrum of patients would have been more appropriate. Additionally, we were not able to analyze demographic factors such as gender differences, household income or literacy level in transitional readiness accurately due to limited sample size. Previous studies have demonstrated that females tend to demonstrate higher transition readiness as they tend to mature earlier (21). Other studies demonstrated positive associations for transition readiness in higher median household income (25), while parent education and household size has not shown to have significant association with transition readiness (24). Similarly, On the other hand, some of the advantages of this study is the use of a provider administered questionnaire, as opposed to a selfadministered questionnaire. Hence, it does not solely rely on patient self-report, instead the validity of the patient's responses can be assessed by the health provider either during the interview and/or by examining specific information contained in a patient's medical chart. Also, the assessment tool uses a feedback approach to help guide health-care providers to praise the adolescent on knowledge/skills they have already mastered, help them improve on tasks they perform adequately, and help them focus on the areas where they have the lowest competencies (16). 


\section{Conclusion:}

In conclusion, there is a dire need to prioritize adolescent health care practice, health care facilities, clinical education and research in this region of the world. This could be accomplished through the development of adolescent health care centers that bring together expert interdisciplinary care, excellent health provider training, and cutting-edge adolescent health research to provide leadership throughout the region and further both the health of adolescents and their access to high-quality, holistic health services (34).

\section{Abbreviations:}

HCT: Health Care Transition

AYA: Adolescents and Young Adults

SLE: Systemic lupus erythematosus

JIA: Juvenile Idiopathic Arthritis

GCC: Gulf Cooperation Council

AAP: American Academy of Pediatrics

AAFP: American Academy of Family Physicians

ACP: American College of Physicians

CARRA: Childhood Arthritis and Rheumatology Research Alliance

\section{Declarations:}

\section{Ethical Approval and Consent to participate}

Ethical approval for the research project was obtained from both Medical Research Ethical Committee in each institution.

Written informed consent was obtained from both patient and parents of the patient

\section{Availability of supporting data}

The datasets used and/or analyzed during the current study are available from the corresponding author upon request

\section{Competing interests}


The authors declare that they have no competing interests

\section{Funding}

There was no funding source for this work

\section{Authors' contributions}

RA drafted the manuscript. RS and ZH contributed to data acquisition. RA and SR contributed to data analysis. All authors and contributed to the critical revisions of the manuscript. All authors read and approved the final manuscript.

\section{Acknowledgements}

Not applicable

\section{Consent for publication}

Not applicable

\section{References:}

1. Petty RE . Prognosis in children with rheumatic diseases: justification for consideration of new therapies. Rheumatology 1999;38:739-42.

2. Lovell DJ , Giannini EH , Reiff A, et al . Etanercept in children with polyarticular juvenile rheumatoid arthritis. pediatric rheumatology collaborative Study Group. N Engl J Med 2000;342:763-9.

3. Stoll ML , Cron RQ . Treatment of juvenile idiopathic arthritis in the biologic age. Rheum Dis Clin North Am 2013;39:751-66.

4. Magnani A, Pistorio A, Magni-Manzoni S , et al. Achievement of a state of inactive disease at least once in the first 5 years predicts better outcome of patients with polyarticular juvenile idiopathic arthritis. J Rheumatol 2009;36:628-34.

5. Wallace CA, Giannini EH, Spalding SJ , et al . Childhood arthritis and rheumatology research alliance: trial of early aggressive therapy in polyarticular juvenile idiopathic arthritis. Arthritis Rheum 2012;64:2012-21.

6. Hazel, E., Zhang, X., Duffy, C.M. et al. High rates of unsuccessful transfer to adult care among young adults with juvenile idiopathic arthritis. Pediatr Rheumatol 2010; 8, 2

7. Selvaag AM, Aulie HA, Lilleby V, Flatø B. Disease progression into adulthood and predictors of longterm active disease in juvenile idiopathic arthritis. Ann Rheum Dis. 2016; 75(1):190-5.

8. Hersh A, von Scheven E, Yelin E. Adult outcomes of childhood-onset rheumatic diseases. Nat Rev Rheumatol. 2011;7(5):290-295. 
9. Groot N, Shaikhani D, Teng YKO, de Leeuw K, Bijl M, Dolhain RJEM, et al. Long-term clinical outcomes in a cohort of adults with childhood-onset systemic lupus erythematosus. Arthritis Rheum. 2019; 71:290-301.

10. Schlichtiger, J., Haas, JP., Barth, S. et al. Education and employment in patients with juvenile idiopathic arthritis - a standardized comparison to the German general population. Pediatr Rheumatol 2017; 15:45

11. Bouaddi I, Rostom S, El Badri D, Hassani A, Chkirate B, Amine B, et al. Impact of juvenile idiopathic arthritis on schooling. BMC Pediatr. 2013;13:2.

12. Gabriel P, McManus M, Rogers K, White P. Outcome evidence for structured pediatric to adult health care transition interventions: a systematic review. J Pediatr. 2017;188:263-269.e215.

13. Blum RW, Garell D, Hodgman CH, Jorissen TW, Okinow NA, Orr DP, et al. Transition from childcentered to adult healthcare systems for adolescents with chronic conditions. A position paper of the Society for Adolescent Medicine. J Adolesc Health. 1993;14(7):570-6.

14. Sawicki GS, Lukens-Bull K, Yin X, Demars N, Huang I-C, Livingood W, et al. Measuring the transition readiness of youth with special healthcare needs: validation of the TRAQ-Transition Readiness Assessment Questionnaire. JPediatr Psychol. 2011;36(2):160-71.

15. Wood DL, Sawicki GS, Miller MD, Smotherman C, Lukens-Bull K, Livingood WC, et al. The Transition Readiness Assessment Questionnaire (TRAQ): its factor structure, reliability, and validity. Acad Pediatr. 2014;14(4):415-22.

16. Ferris ME, Harward DH, Bickford K, Layton JB, Ferris MT, Hogan SL, et al. A clinical tool to measure the components of healthcare transition from pediatric care to adult care: the UNC TR(x)ANSITION scale. Ren Fail. 2012;34(6):744-53.

17. Ferris M, Cohen S, Haberman C, Javalkar K, Massengill S, Mahan JD, et al. Self-management and transition readiness assessment: development, reliability, and factor structure of the STARx questionnaire. J Pediatr Nurs. 2015;30(5):691-9.

18. Moynihan M, Saewyc E, Whitehouse S, Paone M, McPherson G. Assessing readiness for transition from paediatric to adult health care: revision and psychometric evaluation of the Am I ON TRAC for adult are questionnaire. J Adv Nurs. 2015;71(6):1324-35.

19. Klassen AF, Grant C, Barr R, Brill H, Kraus de Camargo O, Ronen GM, et al. Development and validation of a generic scale for use in transition programmes to measure self-management skills in adolescents with chronic health conditions: the TRANSITION-Q. Child Care Health Dev. 2015;41:54758.

20. Sawicki GS, Garvey KC, Toomey SL, Williams KA, Chen Y, Hargraves JL, et al. Development and validation of the adolescent assessment of preparation for transition: a novel patient experience measure. J Adolesc Health. 2015; 57(3):282-7.

21. Parfeniuk, Sarah, Petrovic, Kristin, Maclsaac, Peggy Lynn, Cook, Karen A. and Rempel, Gwen R. Transition readiness measures for adolescents and young adults with chronic health conditions: a systematic review" Journal of Transition Medicine, 2020; 1: 2. 
22. Cantu-Quintanilla G, Ferris M, Otero A, Gutierrez-Almaraz A, Valverde-Rosas S, Velazquez-Jones L, et al. Validation of the UNC TRXANSITION Scale Version 3 among Mexican adolescents with chronic kidney disease. J Pediatr Nurs 2015;30:e71-81.

23. Fenton N, Ferris M, Ko Z, Javalkar K, Hooper SR. The relationship of health care transition readiness to disease-related characteristics, psychosocial factors, and health care outcomes: preliminary findings in adolescents with chronic kidney disease. J Pediatr Rehabil Med 2015;8:13-22.

24. Javalkar K, Fenton N, Cohen S, Ferris M. Socioecologic factors as predictors of readiness for selfmanagement and transition, medication adherence, and health care utilization among adolescents and young adults with chronic kidney disease. Prev Chronic Dis 2014;11:E117.

25. Javalkar K, Johnson M, Kshirsagar AV, Ocegueda S, Detwiler RK, Ferris M. Ecological factors predict transition readiness/selfmanagement in youth with chronic conditions. J Adolesc Health 2016;58:40-6

26. C. Haub, T. Kaneda. World population data sheet 2013. Population Reference Bureau, Washington, DC (2013). http://www.prb.org/pdf13/2013-population-data-sheet_eng.pdf

27. A.S. Al-Makadma, M. Al-Tanni. The perception of adolescent medicine among health care professionals in Saudi Arabia.J Adol Health, 2010; 47: 608-609

28. Eleftheriou D, Isenberg DA, Wedderburn LR, loannou Y. The coming of age of adolescent rheumatology. Nat Rev Rheumatol. 2014;10(3):187-93.

29. McDonagh, J.E., Farre, A. Transitional Care in Rheumatology: a Review of the Literature from the Past 5 Years. Curr Rheumatol Rep 2019; 21:57

30. McManus, M., White, P., Barbour, A., Downing, B., Hawkins, K., Quion, N., Tuchman, L., Cooley, W. C., \& McAllister, J. W. Pediatric to Adult Transition: A Quality Improvement Model for Primary Care. Journal of Adolescent Health. 2015; 56(1): 73-78.

31. Foster HE, Minden K, Clemente D, Leon L, McDonagh JE, Kamphuis S, et al. EULAR/PReS standards and recommendations for the transitional care of young people with juvenile-onset rheumatic diseases. Ann Rheum Dis. 2016;76(4):639-46.

32. Clemente, D., Leon, L., Foster, H. et al. Transitional care for rheumatic conditions in Europe: current clinical practice and available resources. Pediatr Rheumatol 2017; 15: 49

33. Johnson K, Edens C, Sadun RE, et al; for the CARRA Transition Workgroup. Differences in health care transition views, practices, and barriers amongst North American pediatric rheumatology clinicians from 2010 to 2018. Rheumatol 2021;48(9):1442-1449.

34. Al Makadma A. Adolescent health and health care in the Arab Gulf countries: Today's needs and tomorrow's challenges, International Journal of Pediatrics and Adolescent Medicine. 2017; 4(1): 1-8.

\section{Figures}


Fig. 1. Mean and $95 \%$ confidence interval of TIS in different age ...

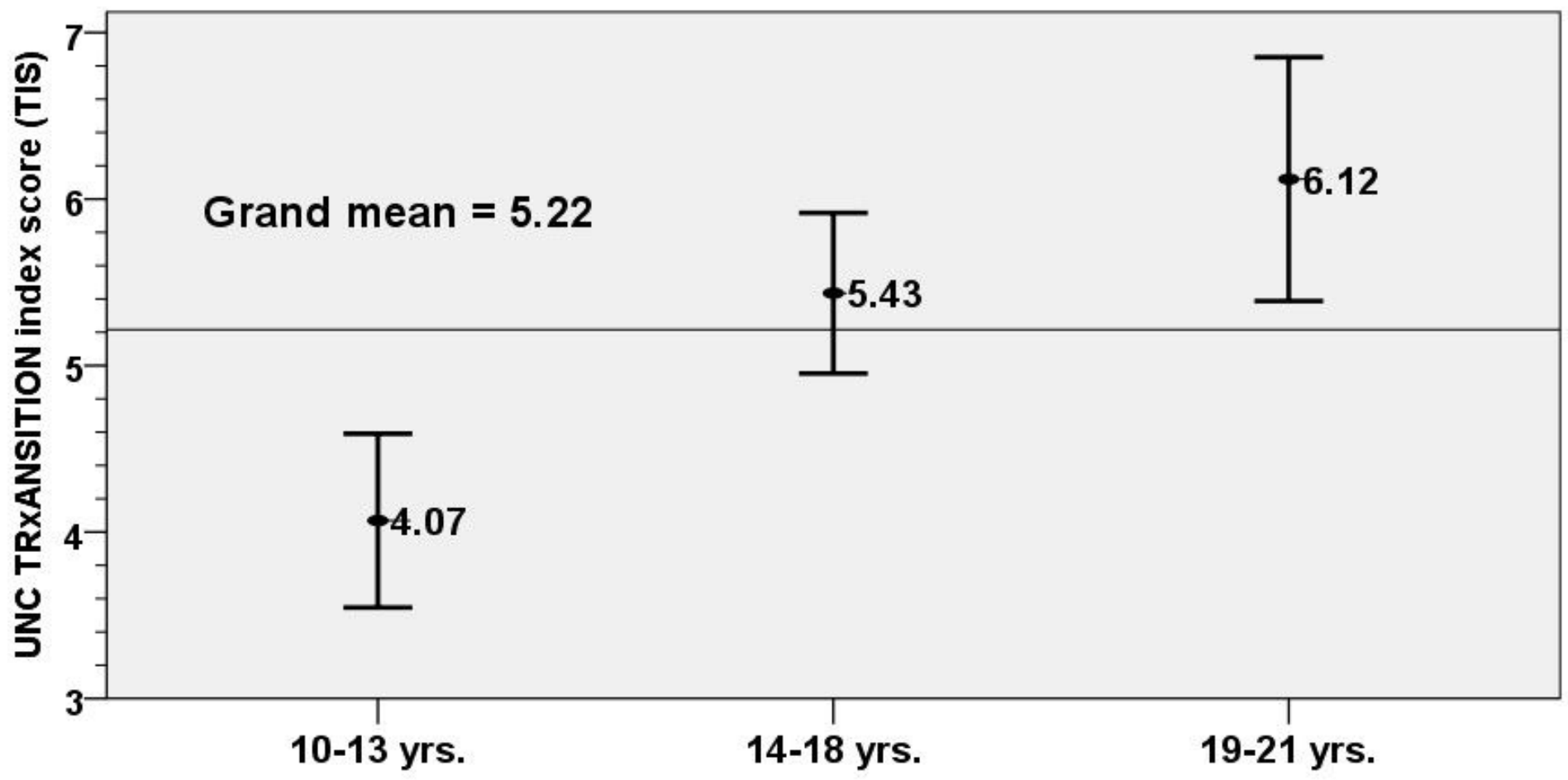

Figure 1

See image above for figure legend.

Fig. 2. Mean TIS in significant domains in different age groups

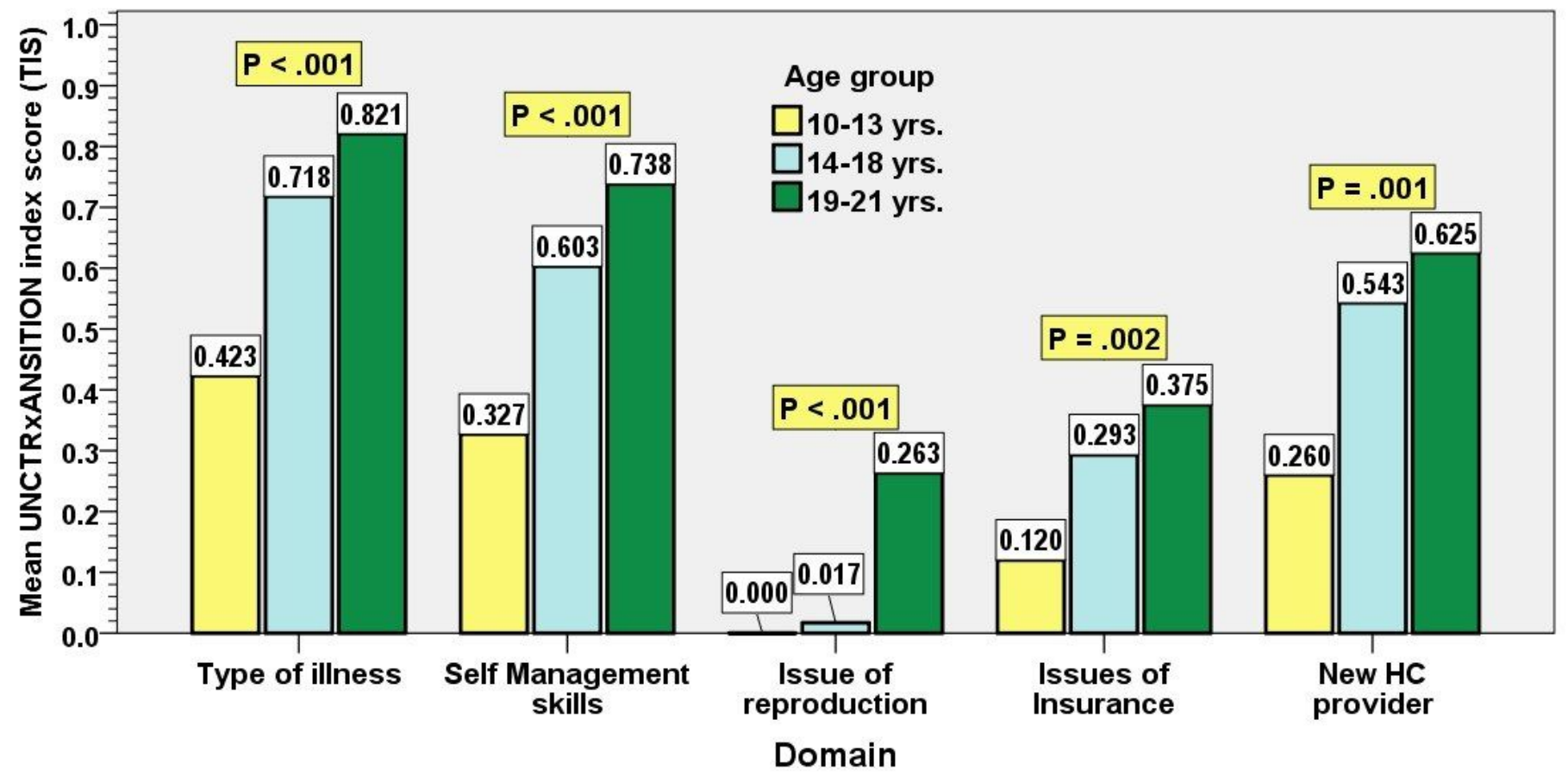


Figure 2

See image above for figure legend.

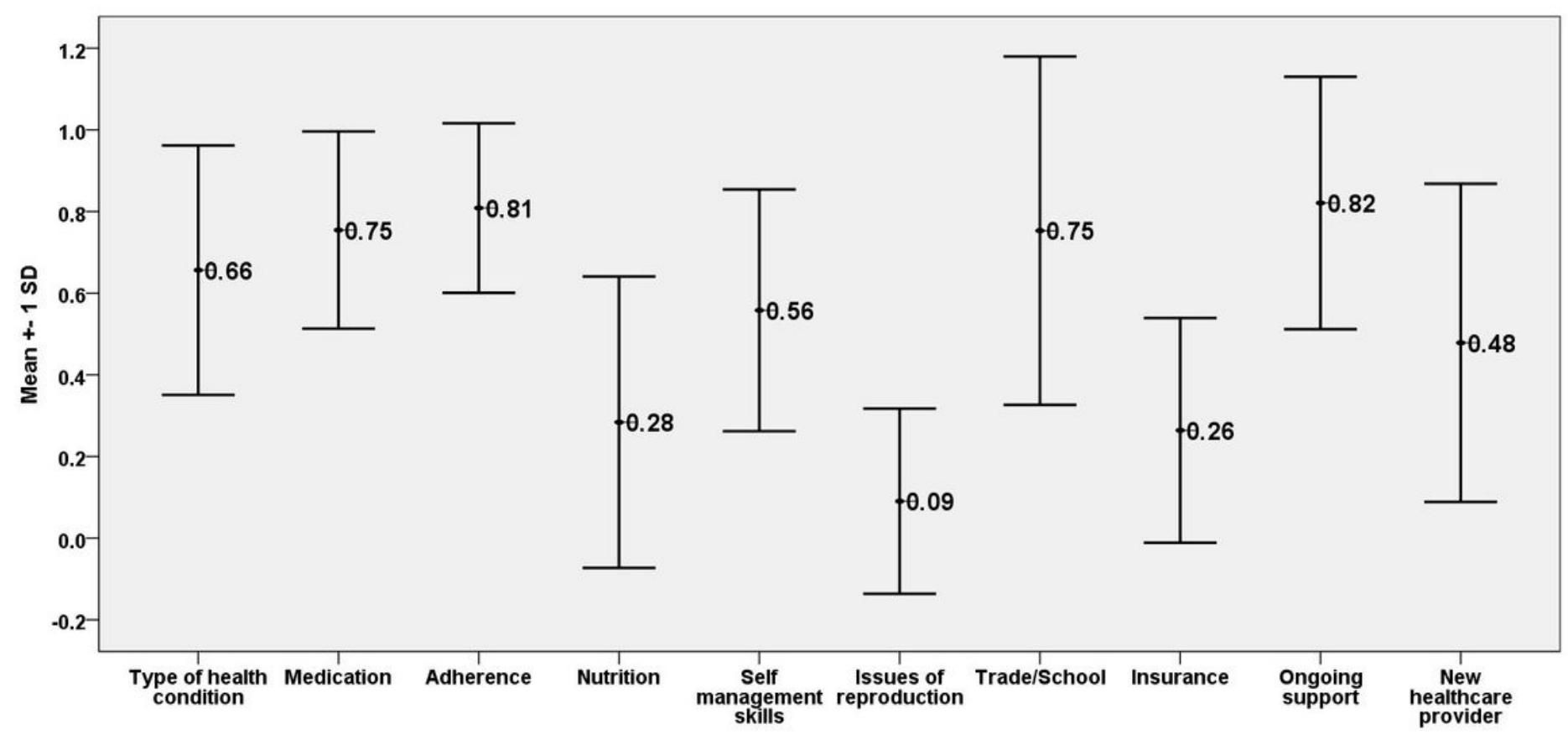

Figure 3

Mean UNC TRXANSITION Scale in 10 subdomains 